\title{
Cognitive deficits and their relationship to other neurological complications in chronic alcoholic patients
}

\author{
MASSIMO FRANCESCHI, GIULIO TRUCI, GIANCARLO COMI, LUIGI LOZZA, \\ PAOLO MARCHETTINI, GIUSEPPE GALARDI, SALVATORE SMIRNE
}

From the Neurology Department, University of Milan, School of Medicine, $H$ S. Raffaele, Milano, Italy

SUMMARY In randomly selected chronic alcoholics hospitalised for the first time for detoxification a high prevalence $(68 \%)$ of cognitive deficits was found. Peripheral neuronal damage was seen in $74 \%$, autonomic neuronal damage in $24 \%$. Cognitive deficits were not correlated with age, daily ethanol intake, duration of alcohol abuse or severity of liver damage. There was no correlation of peripheral, autonomic and central nervous system damage. Alcohol-induced damage of the nervous system is a common complication of chronic alcoholism, whose clinical importance often obscures possible concomitant liver damage.

Alcohol-induced brain damage and peripheral neuropathy have been recognised and extensively studied for a century. ${ }^{1}$ More recently, ${ }^{2}$ autonomic neuropathy has been found to be a relatively common and life-threatening complication of alcohol abuse. Moreover, in young alcoholic men there is a far greater prevalence of brain damage, evaluated by means of psychometric testing, than of liver damage. ${ }^{3}$ Despite this evidence and its importance for prognosis of chronic alcoholism, neurological complications are generally neglected, as compared to the great attention paid to the liver or the psychological or social problems caused by alcohol abuse. We studied the neurological complications, evaluated by means of neuropsychological and neurophysiological testing, in a group of chronic alcoholic patients. This report describes the prevalence and the clinical importance of alcohol-induced brain damage, evaluated by psychometric tests, and correlations with peripheral and autonomic nerve damage, with liver function and with other features of chronic alcoholic patients.

\section{Subjects}

Fifty patients, 41 men and nine women, aged $30-50$ years (mean 42), hospitalised for alcoholic detoxification, were

Address for reprint requests: M Franceschi, Neurology Dept, S. Raffaele H., 20132 Milano, Italy.

Received 23 March 1983 and in revised form 21 Feburary 1984. Accepted 5 April 1984 randomly selected for the study. All the subjects were informed of the aim of the study and gave their consent. For 14 patients $(28 \%)$, alcohol abuse had been an important problem for less than 10 years, for 25 patients $(50 \%) \stackrel{\varnothing}{\varrho}$ for 10-20 years and for 11 patients $(22 \%)$ for more than 20 years. Average daily ethanol intakes were $100-150 \mathrm{~g}$ for 20 patients $(40 \%), 150-300 \mathrm{~g}$ for 22 patients $(44 \%)$ and more than $300 \mathrm{~g}$ for eight patients $(16 \%)$. On the basis of biopsy, scintiscan or abdominal ultrasound and haematological parameters, 10 patients $(20 \%)$ had no liver ? damage, 30 patients $(60 \%)$ moderate and 10 patients $(20 \%)$ severe liver damage. Patients suspected to have hepatic or Wernicke's encephalopathy were excluded from the study.

All the neurophysiological and neuropsychological tests were performed two to three weeks after alcohol withdrawal, ${ }^{4}$ while the patients, untreated with drugs, were still in hospital.

\section{Methods}

The neuropsychological performances of alcoholic patients were compared with those of randomly selected nondrinking controls, 16 men and four women, aged 28-53 (mean 41), hospitalised for minor surgical or orthopaedic disorders. The alcoholic patients and the controls did not significantly differ in age, sex distribution, education, social status or work activities. The battery of tests, in common clinical use, were administered in two 45-minute sessions.

The first session included the Konzentrations Verlaufs Test (KVT), to evaluate attention and concentration; 6 Raven's Progressive Matrices 1938 (PM 38), to estimate intelligence factor " $\mathrm{g}$ "; ; and the Wechsler Memory Scale (WMS), to evaluate global Memory Quotient (MQ), short term verbal memory (STM verb), long term verbal mem- 
ory (LTM), short term visual memory (STM vis) and learning. ${ }^{8}$ The second session included the "Upside-down Figure Test" (UDFT), for evaluation of spatial gnosia; ${ }^{9}$ the Rey Test (RT), for evaluation of visual gnosia; ${ }^{10}$ the following subtests of the Wechsler Adult Intelligence Scale (WAIS): (1) "block design", to appraise eye-hand coordination and spatial analysis; (2) "similarities", to test abstractive reasoning; (3) "digit-symbol substitution", to test psychomotor ability; (4) "picture arrangement", to test reasoning." All tests were administered by the same physician, trained in administering psychological tests, who knew the patient's group, while the psychologist who scored the tests and the statistician who analysed the data were unaware of it.

Standard scoring was used for the tests, when available (KVT, UDFT, WMS and WAIS subtests). Learning was evaluated by means of repetitive administration of the WMS subtest "word association": subjects who learned all the items at first administration had higher scores, while others scored proportionally lower.

Nerve conduction velocity of four peripheral nerves (median, ulnar, sural and peroneal nerves) and electromyography of two muscles (first interosseus dorsalis and tibialis anterior muscles) were studied in each patient. Peripheral neuropathy was diagnosed as "moderate" when two peripheral nerves or one peripheral nerve and one muscle were abnormal; as "severe" if more than two peripheral nerves and one muscle were affected. Abnormalities of only one peripheral nerve or one muscle were not considered to be signs of alcoholic peripheral neuropathy.

Autonomic nerve functioning in alcoholic patients was evaluated by (a) postural blood pressure changes; ${ }^{12}$ (b) the handgrip test; ${ }^{12}$ (c) changes in heart rate during the Valsalva manoeuvre ${ }^{13}$ and deep breathing. ${ }^{14}$ Autonomic neuropathy was diagnosed when at least one of these tests was abnormal.

For statistical analysis of the data, ANOVA, regression analysis, Spearman's tests and Radhakrishna's discriminant analysis ${ }^{15}$ were used as appropriate.

Table Mean scores $( \pm S D)$ for controls and alcoholic patients in neuropsychological tests and prevalence of impaired alcoholic patients according to each test

\begin{tabular}{lccc}
\hline & $\begin{array}{l}\text { Controls } \\
n=20\end{array}$ & $\begin{array}{l}\text { Alcoholics } \\
n=50\end{array}$ & $\begin{array}{l}\text { Impaired } \\
\text { alcoholics } \\
n(\%)\end{array}$ \\
\hline PM 38 & $41 \cdot 1 \pm 10 \cdot 1$ & $27 \cdot 5 \pm 11 \cdot 5^{*}$ & $15(30)$ \\
KVT & $94 \cdot 9 \pm 12 \cdot 9$ & $80 \cdot 8 \pm 14 \cdot 6 \dagger$ & $11(22)$ \\
UDFT & $5 \cdot 3 \pm 1 \cdot 5$ & $4 \cdot 1 \pm 2 \cdot 1^{*}$ & $14(28)$ \\
RT & $36 \cdot 5 \pm 9 \cdot 5$ & $25 \pm 8 \cdot 1^{\dagger}$ & $14(28)$ \\
WAIS subtests & $32 \pm 8$ & $20 \cdot 7 \pm 9 \cdot 8 \dagger$ & $12(24)$ \\
$\quad$ Block design & $15 \cdot 9 \pm 3 \cdot 3$ & $11 \pm 4 \cdot 4^{*}$ & $18(36)$ \\
Similarities & $19 \cdot 9 \pm 4 \cdot 9$ & $15 \cdot 9 \pm 5 \cdot 7^{*}$ & $8(16)$ \\
Pictures & $19 \cdot 6 \pm 13 \cdot 1$ & $24 \pm 10^{\dagger} \cdot{ }^{\dagger}$ & $13(26)$ \\
Digit-symbol & $42 \cdot 6 \pm 13 \cdot 1$ & & \\
WMS & $95 \cdot 8 \pm 15 \cdot 5$ & $80 \pm 16 \dagger$ & $10(20)$ \\
MQ & $10 \cdot 2 \pm 1 \cdot 6$ & $8 \cdot 7 \pm 2 \cdot 1^{*}$ & $6(12)$ \\
STM Verb & $12 \cdot 2 \pm 4$ & $8 \cdot 9 \pm 4 \cdot 2^{*}$ & $7(14)$ \\
LTM & $11 \pm \pm 3$ & $7 \cdot 6 \pm 4^{*}$ & $12(24)$ \\
STM Vis & $2 \cdot 9 \pm 1 \cdot 7$ & $1 \cdot 8 \pm 1 \cdot 7^{*}$ & $8(16)$ \\
Learning & & & \\
\hline
\end{tabular}

Abbreviations are listed in the text.

$*=p<0.05$.

$\dagger=\mathrm{p}<0.001$

\section{Results}

The table shows mean scores $( \pm \mathrm{SD})$ in neuropsychological tests for alcoholic patients and controls and their statistical analysis. In all tests, cognitive performances of the group of alcoholic patients were significantly lower than those of the control group. If we take as normal the mean value $\pm 2 \mathrm{SD}$ for each test of the control group, 16 patients (32\%) were unimpaired in cognitive tests. Cognitive deficits of patients were not significantly correlated with age, sex, social status or work activity, daily ethanol intake, duration of alcohol abuse or severity of liver damage. Education, as expressed in years of school attendance, was positively correlated with higher scoring in the PM 38, WAIS subtests "similarities" and "digit-symbol substitution", WMS MQ and the subtest for short-term visual memory.

In our sample, there was no peripheral neuropathy in 13 patients $(26 \%)$, it was moderate in $23(46 \%)$ and severe in $14(28 \%)$. There was no autonomic neuropathy in 38 patients $(76 \%)$, but it was serious in 12 patients $(24 \%)$.

The neuropsychological performance of alcoholic patients was not correlated with the integrity or severity of damage to either peripheral or autonomic nerves.

\section{Discussion}

As expected, the alcoholic group scored lower than the control group in all the neuropsychological tests. This is in agreement with almost all previous reports with similar experimental designs, ${ }^{16-19}$ though there are some exceptions. ${ }^{20}$ Recent studies have suggested that deficits found at one interval after alcohol withdrawal may be significantly reduced after additional time has elapsed. ${ }^{21}$ In any case, much recovery occurs between two and three weeks after drinking ceases ${ }^{15}$ and we tested our patients after this interval.

The cognitive deficits we observed indicate dysfunctions of reticulo-mesencephalic (KVT) and limbic structures (WMS), as well as of the right (UDFT, "block design") and the left hemispheres (RT, "similarities", "picture arrangement" and "digit-symbol substitution") and the cerebral cortex as a whole (PM 38). These neuropsychological data agree with computed tomographic ${ }^{223}$ and neuropathological ${ }^{24} 25$ findings of widespread cerebral atrophy. We could not find any correlation between cognitive deficits and the duration of excessive drinking, daily ethanol intake or presence of liver damage. Though not logically to be expected, this agrees with previous studies. ${ }^{422} 26$ These data 
seem to indicate the existence of separate factors in tolerance to prolonged toxic effects of alcohol on neurons. Malnutrition, repeated head injuries, withdrawal fits or concomitant liver dysfunction seem to be secondary in the pathogenesis of cognitive impairment. ${ }^{26}$

As commonly observed in Italy, alcoholic men outnumbered alcoholic women four to one. This imbalance prevents accurate statistical analysis of sex differences in alcohol-induced cognitive impairment, though our men and women seem to have similar cognitive deficits. The only significant difference between sexes was the higher prevalence of peripheral neuropathy and liver damage in the alcoholic women (each in eight of nine).

Alcoholic-induced peripheral neuropathy was not seen in approximately one third of our patients, and autonomic neuropathy was not seen in three quarters. The lack of significant association or correlation of peripheral, autonomic and central nervous system damage is particularly interesting. In other words, for alcoholic patients the presence of peripheral neuropathy is by no means predictive of cognitive deficits or of autonomic neuropathy or vice versa. This finding, in good agreement with clinical experience, supports the hypothesis that ethanol can damage the peripheral, autonomic and central nervous systems by different effects. Central neurons might be more susceptible than peripheral and autonomic ones to thiamine deficiency, in which congenital factors play an important role. ${ }^{27}$ Moreover, alcoholism is associated with reduced cerebral blood flow. ${ }^{28}$ Finally, though our patients were all normotensives, their cerebral neurons might have suffered from transient hypertensive episodes during either alcohol-induced stress reactions ${ }^{29}$ or occasional alcohol withdrawal. ${ }^{30}$

As a group, alcohol-induced neurological damage assumes paramount clinical importance, often obscuring possible concomitant liver disease.

\section{References}

'Wernicke C. Die acute hamorrhagische Polioencephalitis superior. Lehrbuch der Gehirnkrankheiten 1881;1:229-42.

${ }^{2}$ Duncan G, Johnson RH, Lambie DG, Witheside EA. Evidence of vagal neuropathy in chronic alcoholis. Lancet 1980;ii: 1053-7.

${ }^{3}$ Lee K, Moller L, Hardt F, Haubek A, Jensen E. Alcohol-induced brain damage and liver damage in young males. Lancet 1979;ii:759-61.

"Page RD, Linden JD. "Reversible" organic brain syndrome in alcoholics: a psychometric evaluation. Quarterly Journal of Studies on Alcohol 1974;35:98-107.

s Goldman MS, Williams DL, Klisz DK. Recoverability of psychological functioning following alcohol abuse: prolonged visual-spatial dysfunction in older alcoholics. Consult Clin Psychol 1983;51:370-8.

6 Abels D. Konzentrations-Verlaufs-Test. Gottingen: Hogrefe, 1961.

${ }^{7}$ Raven JC. Matrix Test. London: Mental Health, 1940.

${ }^{8}$ Wechsler S. A standardized memory scale for clinical use. J Psychol 1945;19:87-96.

${ }^{9}$ Luria AR. Le Funzioni Corticali Superiori Nell'Uomo. Giunti, Firenze, 1976

${ }^{10}$ Rey A. Les troubles de la memoire et leur examen psychometrique. Bruxelles: Dessert, 1966.

${ }^{11}$ Wechsler D. The Measurement of Adult Intelligence. Baltimore: William and Wilkins, 1944.

${ }^{12}$ Ewing DJ, Campbell JW, Murray A, Neilson JMM, Clarke BF. Immediate heart rate response to standing: simple test for autonomic neuropathy in diabetics. Br Med J 1978;i:145-7.

${ }^{13}$ Levin AB. A simple test of cardiac function based upon the heart rate changes induced by the Valsalva manoeuvre. Am J Cardiol 1966;18:90-99.

14 Wheeler T, Watkins PJ. Cardiac denervation in diabetes. Br Med J 1973;iv:584-6.

is Radhakrishna S. Discrimination analysis in medicine. Statistician 1964;14:147-67.

${ }^{16}$ Goldstein G, Schelly CH. Field dependence and cognitive, perceptual and motor skills in alcholics. Quarterly Journal of Studies on Alcohol 1971;32:29-40.

17 Blusewicz JM, Dustman RE, Schenkenberg T, Beck EC. Neuropsychological correlates of chronic alcoholism and aging. J Nerv Ment Dis 1977;165:348-55.

${ }^{18}$ Smith HH, Smith LS. WAIS functioning of cirrhotic and non-cirrhotic alcoholics. J Clin Psychol 1977;33: 309-13.

${ }^{19}$ Gilberstadt SJ, Gilberstadt H, Zieve L, Buegel B, Collier RO, Mc Clain CJ. Psychomotor performance defects in cirrhotic patients without overt encephalopathy. Arch Int Med 1980;140:519-21.

${ }^{20}$ Minor brain damage and alcoholism. Editorial. Br Med J 1981;ii:455-6.

${ }^{21}$ Goldman MS. Reversibility of psychological deficits in alcoholics: the interaction of aging with alcohol. In: Wilkinson A, ed. Cerebral Deficits in Alcoholism. Toronto: Addiction Research Foundation, 1982:79105.

${ }^{22}$ Carlen PL, Wilkinson A, Wortzman G, et al. Cerebral atrophy and functional deficits in alcoholics without clinically apparent liver disease. Neurology (NY) 1981;31:377-85.

${ }^{23}$ Acker W, Aps EJ, Majumdar SK, Shaw GK, Thomson AD. The relationship between brain and liver damage in chronic alcoholic patients. J Neurol Neurosurg Psychiatry 1982;45:984-7.

${ }^{24}$ Courville CB. The Effects of Alcohol on the Nervous System of Man. Los Angeles: San Lucas Press, 1955.

${ }^{25}$ Harper CG, Blumbergs PC. Brain weight in alcoholics. $J$ Neurol Neurosurg Psychiatry 1982;45:838-40.

${ }^{26}$ Eckardt MJ, Parker ES, Noble EP, Feldman DJ, Gottschalck LA. Relationship between neuropsychological performance and alcohol consumption in alcoholics. Biol Psychiatry 1978;13:551-65.

${ }^{27}$ Blass J, Gibson G. Abnormality of thiamine requiring 
Cognitive deficits and their relationship to other neurological complications in chronic alcoholic patients 1137

enzyme in Wernicke-Korsakoff syndrome. New Engl J Med 1977;297:1367-70.

${ }^{28}$ Berglund M, Ingvar D. Cerebral blood flow in alcoholism and Korsakoff's psychosis. Quarterly Journal of Studies on Alcohol 1976;37:586-97.
${ }^{29}$ Ogata M, Mendelson JH, Mello KN, Majcrowicz A. Adrenal function and alcoholism. II. Catecholamines. Psychosom Med 1971;33:159-65.

${ }^{30}$ Saunders JB, Beevers DG, Paton A. Alcohol induced hypertension. Lancet 1981;ii:653-6. 